Disponível em

http://www.anpad.org.br/rac

RAC, Rio de Janeiro, v. 20, n. 1, art. 3, pp. 41-63, Jan./Fev. 2016

http://dx.doi.org/10.1590/1982-7849rac20161887

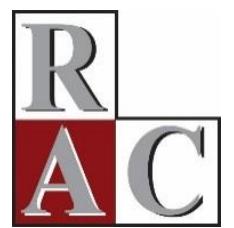

\title{
Tecnologia da Informação Verde: Um Estudo sobre sua Adoção nas Organizações
}

\author{
Green Information Technology: A Study of its Adoption in Organizations
}

Ana Carolina Salles ${ }^{1}$ Ana Paula Ferreira Alves ${ }^{2}$ Décio Bittencourt Dolci ${ }^{1}$ Guilherme Lerch Lunardi ${ }^{1}$

Universidade Federal do Rio Grande ${ }^{1}$ Universidade Federal do Rio Grande do $\mathrm{Sul}^{2}$ 


\title{
Resumo
}

Frente à necessidade de melhor compreender a relação entre estratégias de sustentabilidade e Tecnologia da Informação (TI), objetivou-se, nesta pesquisa, analisar a adoção da TI Verde nas organizações, examinando, mais especificamente, os motivos de adoção, as práticas implantadas, os benefícios percebidos e as dificuldades enfrentadas. Para tanto, foram conduzidos três estudos de caso com empresas de diferentes setores econômicos, sendo fundamental o estudo de Orlikowski (1992) para o correto enquadramento teórico da investigação. Os resultados indicam que as ações, em sua grande maioria, enquadram-se em intersecções formadas pelas três dimensões da sustentabilidade - ambiental, social e econômica - e por uma quarta dimensão, chamada de legal. Além disso, mostram que a implementação parte, inicialmente, da identificação de benefícios financeiros e operacionais, revelando que os benefícios da dimensão ambiental surgem como uma consequência positiva das mudanças provocadas em função de aspectos econômicos e legais. Espera-se que este estudo possa auxiliar executivos no planejamento e na implementação de práticas de TI Verde, assim como pesquisadores interessados nessa temática.

Palavras-chave: TI verde; desenvolvimento sustentável; sustentabilidade; adoção.

\begin{abstract}
Due to the need to better understand the relationship between sustainability strategies and Information Technology (IT), this research aims to analyze the adoption of Green IT initiatives in organizations by specifically examining the adoption motives, implemented practices, perceived benefits and difficulties. To this end, we conducted three case studies with companies from different economic sectors, Orlikowski's research (1992) was fundamental in contributing to the theoretical framework. We found that most Green IT initiatives can be categorized within the intersections formed by the three sustainability dimensions - environmental, social and economic - and a fourth dimension called legal. Furthermore, we found the implementation of these practices started by identifying financial and operational benefits associated with their adoption. The results reveal that environmental benefits emerge as a positive consequence of changes caused by legal and economic aspects. We hope this study can help executives in planning and implementation of Green IT in their organizations, as well as for researchers interested in researching this topic.
\end{abstract}

Key words: green IT; sustainable development; sustainability; adoption. 


\section{Introdução}

As rápidas e contínuas mudanças tecnológicas estimuladas pelo atual modelo capitalista de produção, amplamente disseminado no mundo, culminaram em comportamentos sociais e hábitos de consumo marcados pelo grande desperdício de recursos naturais. Problemas sociais, ambientais e econômicos acabam surgindo decorrentes dessa situação, o que faz da sustentabilidade um tema de vanguarda, chamando a atenção de governos, organizações e comunidade acadêmica (Malhotra, Melville, \& Watson, 2013).

Nesse contexto, a Tecnologia da Informação (TI) tem sido responsável por uma parte significativa dos problemas ambientais com os quais a sociedade contemporânea se depara (Murugesan, 2010). Problemas como o elevado consumo de energia (que contribui, também, para a emissão de gases), a quantidade de insumos não renováveis utilizada na produção de computadores e o descarte de equipamentos obsoletos aparecem como os mais visíveis (Ozturk et al., 2011). Não obstante, a responsabilidade socioambiental começa a ser percebida pelas empresas tanto para a sua sobrevivência (Colwell \& Joshi, 2013) como para a obtenção de vantagem competitiva (Porter \& Linde, 1995). Assim, o gerenciamento inteligente da TI aparece como uma alternativa atrativa para as organizações, não só com o intuito de minimizar os danos causados ao meio ambiente, mas também para desenvolver um ambiente organizacional sustentável, em harmonia com as demandas pró-sustentabilidade da sociedade atual - repercutindo em qualidade de vida, preservação de recursos naturais e vantagem competitiva (Melville, 2010; Orsato, 2006).

Desse modo, tais iniciativas convergem para potencializar mudanças organizacionais, que começam pelas estratégias corporativas, culminando com a parte prática, responsável por concretizar o estado da empresa por meio de processos e tecnologias. Neste conjunto articulado de mudanças, a TI Verde se refere a diferentes atividades implementadas para minimizar os impactos negativos e maximizar os impactos positivos do comportamento humano sobre o meio ambiente, através do uso da TI e dos serviços e produtos por ela oportunizados em todo o seu ciclo de vida (Elliot, 2011).

Frente à necessidade de melhor compreender a relação entre estratégias de sustentabilidade e as práticas verdes aplicadas à área de TI, desenvolveu-se a presente pesquisa que tem por objetivo analisar a adoção da TI Verde nas organizações, examinando os diferentes motivos de adoção, as práticas aplicadas na área de TI, os benefícios percebidos e as principais dificuldades enfrentadas na sua difusão. Para tanto, foram conduzidos três estudos de caso com empresas de diferentes setores econômicos, sendo fundamental o estudo de Orlikowski (1992) para o correto enquadramento teórico da investigação. Ao sugerir que a tecnologia seja entendida do ponto de vista da Teoria da Estruturação de Giddens (1984), Orlikowski (1992) propõe que esta deve ser considerada como uma propriedade estrutural das organizações que desenvolvem ou usam tecnologia. Sob esta perspectiva, conforme mostra a Figura 1, propriedades institucionais influenciam os atores humanos na sua interação com a tecnologia projetando-a, desenvolvendo-a, apropriando-a e modificando-a. Dentre as propriedades institucionais das organizações, estão dimensões organizacionais como estratégias de negócios, ideologias, cultura, mecanismos de controle e, também, pressões ambientais, entre elas: regulamentações governamentais, normas profissionais, estado de conhecimento da tecnologia e condições socioeconômicas. 


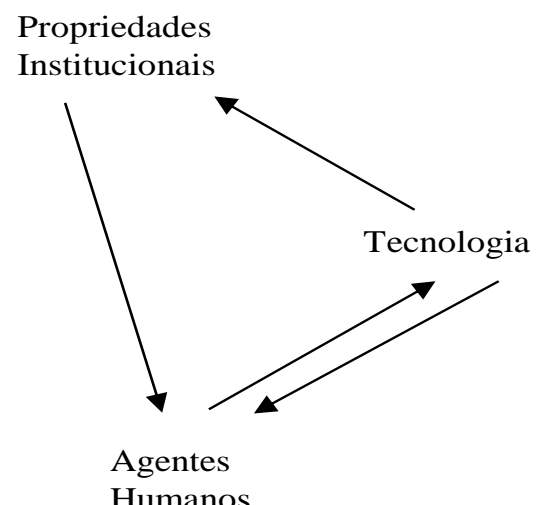

Figura 1. Modelo Estruturacional da Tecnologia

Fonte: Orlikowski, W. (1992). The duality of technology: rethinking the concept of technology in organizations (p. 410). Organization Science, 3(3), 398-427.

Realizada esta introdução, o trabalho divide-se em outras cinco seções. Na primeira, apresenta-se uma revisão da literatura sobre as temáticas Sustentabilidade e TI Verde. Na sequência, descreve-se o método empregado no estudo. Na seção seguinte, expõem-se os resultados obtidos. Após, apresenta-se a sua discussão e, por fim, conclui-se o estudo com as considerações finais, apresentando limitações e possibilidades de novas pesquisas.

\section{A TI Verde e a Sustentabilidade}

Esta seção apresenta conceitos referentes aos dois principais componentes da investigação (Sustentabilidade e TI Verde) e suas relações. Em seguida, destacam-se os principais motivos e atitudes que estimulam a adoção de práticas organizacionais voltadas à TI Verde extraídas da literatura sobre o tema.

\section{Sustentabilidade}

O grande avanço científico e tecnológico das últimas décadas desconsiderou a conexão entre economia e ecologia, tendo como impacto negativo o aumento da degradação ambiental do planeta - a partir da diminuição de reservas de recursos naturais não renováveis, o desequilíbrio dos ecossistemas, o aumento de resíduos sólidos per capita, a redução de espaço para o seu armazenamento e os níveis elevados de poluição da água, do ar e do solo (Slaper \& Hall, 2011; Vanchon \& Klassen, 2006). Nesse contexto, as preocupações quanto a um futuro socialmente justo para a humanidade e a crescente conscientização global sobre os problemas ambientais incentivaram a criação do conceito de desenvolvimento sustentável (Hopwood, Mellor, \& O’Brien, 2005). Em 1987, o relatório Our Common Future, divulgado pela Comissão Mundial sobre o Meio Ambiente e o Desenvolvimento, definiu desenvolvimento sustentável como aquele que "satisfaz às necessidades do presente, sem comprometer a capacidade das gerações futuras de suprir suas necessidades" (World Commission on Environment and Development [WCED], 1987, p. 43).

Uma das interpretações mais disseminadas foi proposta por Elkington (2001), ao introduzir o conceito do triple bottom line (TBL), entendendo que a sustentabilidade deve incorporar aspectos sociais, ambientais e econômicos. Para Elkington (2001), a dimensão ambiental abrange a preocupação em pensar formas de produzir e consumir que garantam o processo de autorreparação dos ecossistemas. A dimensão social envolve esforços para erradicar a pobreza e definir um padrão para uma vida digna, com distribuição justa e equitativa do consumo dos bens naturais e serviços, entre todos os habitantes do planeta. A dimensão econômica, por sua vez, inclui economia formal e informal, no sentido de prover 
serviços para os indivíduos e grupos, de modo a aumentar a renda monetária e o padrão de vida dos indivíduos.

A tradução da sustentabilidade e do desenvolvimento sustentável, na prática, ocorre a partir de um processo de descoberta, execução, criação e adaptação das instituições, de políticas, estratégias e tecnologias para produzir uma sociedade justa (Hopwood et al., 2005). De tal modo, organizações passaram a ser pressionadas pela sociedade a adotar práticas mais sustentáveis em suas atividades. Iniciativas pró-sustentabilidade vêm sendo propostas ou adotadas por organizações na tentativa de repensar processos e produtos que devem ser modificados de forma a reduzir impactos socioambientais (Vanchon \& Klassen, 2006), indicando que as empresas podem estar mais conscientes a respeito da sustentabilidade e que esta variável pode representar diferenciação e competitividade no mercado em que atuam (Kiron, Kruschwitz, Haanaes, \& Velken, 2012).

\section{A TI verde}

O efeito negativo da TI na sustentabilidade ambiental e a relevância do tema sustentabilidade estimulou o interesse da academia na realização de pesquisas sobre essa temática (Watson, Boudreau, $\&$ Chen, 2010). Mais especificamente na área de TI, esse movimento vem sendo referido como TI Verde (Molla et al., 2008), um termo genérico para as medidas e atividades do departamento de TI das empresas que visam contribuir para os objetivos orientados pela sustentabilidade empresarial e pela responsabilidade social corporativa (Schmidt, Erek, Kolbe, \& Zarnekow, 2010). Ainda que a TI venha representando uma parte significativa dos problemas ambientais, a abordagem chamada de TI-peloverde não considera mais a tecnologia como uma razão para os problemas ambientais, mas sim como uma potencial solução (Loss et al., 2011).

Segundo Lunardi, Frio e Brum (2011), a TI Verde ainda é um movimento recente, por isso, ainda não apresenta um conceito inteiramente definido, tão pouco representa um conjunto predeterminado de práticas aceitas e aplicadas por todas as organizações. Nesse sentido, a Tecnologia de Informação Verde pode ser considerada como aquela que se utiliza de estudos para projetar, fabricar, utilizar e descartar produtos e subprodutos computacionais, pressupondo efetividade para garantir níveis mínimos de impactos negativos ao meio ambiente (Murugesan, 2010). Além disso, está atenta ao desperdício, à economia da eficiência energética e ao custo total de propriedade, englobando o custo de descarte e reciclagem. Compreende, ainda, instrumentos para controlar, orientar e comunicar as práticas usadas (Schmidt et al., 2010).

A TI Verde pode ser vista como uma abordagem holística e sistemática para enfrentar os desafios da infraestrutura de TI, dos impactos ambientais das atividades de TI, do suporte de TI para as práticas empresariais ambientalmente corretas e do papel da TI na economia de baixo carbono (Molla et al., 2008). Ao utilizar uma visão sociotécnica, Brooks, Wang e Sarker (2010) classificaram a TI Verde em: (a) iniciativas que empregam a infraestrutura de TI na mudança de processos e/ou práticas organizacionais para melhorar a eficiência energética e reduzir os impactos ambientais; e (b) produtos de TI ambientalmente corretos. Desse modo, a TI Verde pode favorecer a inserção de estratégias ambientalmente favoráveis nas organizações, bem como introduzir produtos ambientalmente corretos no mercado.

\section{Motivos e atitudes que impulsionam a TI Verde}

Diversos autores têm salientado as vantagens que uma organização tem por ser considerada verde (Brooks, Wang, \& Sarker, 2010; Dyllick \& Hockerts, 2002; Murugesan, 2010), sendo os benefícios ambientais e os financeiros os principais (Brooks et al., 2010). Os benefícios ambientais estão relacionados à ecoequidade, que se refere ao direito igualitário entre as gerações atuais e futuras quanto aos recursos naturais disponíveis. Já os benefícios financeiros estão associados à ecoeficiência, que diz respeito à entrega de produtos e serviços com preços competitivos, que ao mesmo tempo suprem a demanda dos consumidores e possuem menor impacto no meio ambiente (Dyllick \& Hockerts, 2002). 
O uso ineficiente da TI, além de prejudicar o meio ambiente, pode resultar em maiores custos para as organizações, fato que pode fazê-las perder vantagens competitivas importantes (Melville, 2010). Organizações que não se preocupam com a busca e a atualização de conhecimentos referentes à sustentabilidade de suas atividades tendem a aumentar os custos de produção, em virtude dos investimentos de capital e custos de operação, prejudicando o resultado financeiro da organização (Kim \& Ko, 2010). Além disso, outros fatores podem estimular o uso eficiente da TI, como a concessão de incentivos fiscais a empresas que contribuem para o meio ambiente investindo em tecnologias de produção limpas e eficientes e, portanto, mais sustentáveis (Watson et al., 2010).

Por outro lado, as organizações, como consequência dos efeitos causados ao meio ambiente na produção de seus bens e serviços, também sofrem pressões externas para a solução do problema e passam a ser responsáveis pela redução de impactos e adoção de posturas menos degradantes. A concorrência, por exemplo, faz com que as empresas tentem tornar as suas operações mais eficientes, seja adquirindo produtos eletroeletrônicos que consumam menos energia, seja reduzindo a emissão de gases. Os consumidores e os grupos ambientais (como o Greenpeace), por sua vez, também se tornam ativistas pela sustentabilidade, pressionando as organizações a adotar inovações em prol da ecoeficiência e da ecoequidade. Os governos, assim como as instituições de classe, também acabam sendo agentes ativistas em favor da sustentabilidade empresarial, uma vez que têm legitimidade para instituir leis e regulamentações que alteram o padrão de produção e, inclusive, alteram a base de competição entre as empresas, forçando-as a buscar competitividade por meio da adoção de posturas mais responsáveis e ambientalmente corretas frente aos seus stakeholders (Watson et al., 2010).

Percebe-se, desse modo, que são diversos os motivos que estimulam a adoção de práticas de TI Verde. Molla e Abareshi (2012) classificam esses motivos em quatro categorias: aqueles relacionados à ecoeficiência, à ecoeficácia, à ecorresponsividade e à ecolegitimidade. Os motivos relacionados à ecoeficiência refletem o desejo de melhorar a sustentabilidade ambiental associada aos objetivos de redução de custos. Já a ecoeficácia tem origem no sistema de valores e crenças da organização para alcançar resultados sociopolíticos, além da preocupação com o meio ambiente. A ecorresponsividade refere-se ao desejo de melhorar a sustentabilidade ambiental por meio de oportunidades verdes ou como resposta a ações dos concorrentes, clientes e fornecedores. E, por fim, os motivos associados à ecolegitimidade, na qual se desenvolvem ações em prol da sustentabilidade ambiental devido a diferentes pressões políticas e sociais a que estão expostas as organizações.

Nessa perspectiva, colocar em prática a TI Verde exige mudanças em termos de tecnologias e de comportamento. As mudanças tecnológicas se concentram em melhorar a infraestrutura de TI e de negócios para torná-las ambientalmente corretas. As mudanças de comportamento, por conseguinte, podem ser realizadas através do agir de maneira ambientalmente responsável e pelo desenvolvimento e aplicação de políticas organizacionais alinhadas com a estratégia de TI da organização. Bose e Luo (2012) afirmam que boa parte dos estudos disponíveis indica que a atuação da área de TI é crítica para enfrentar o problema, porém necessita do envolvimento da organização como um todo para a obtenção de resultados significativos.

\section{Método}

Caracteriza-se o presente estudo como uma pesquisa qualitativa, de caráter exploratóriodescritivo, sendo desenvolvido a partir de um estudo de casos múltiplos junto a três empresas brasileiras, com atuação no estado do Rio Grande do Sul. Encontra-se, nesta abordagem metodológica, a vantagem das múltiplas fontes de evidência para solucionar problemas de pesquisa que ressaltam o como e o porquê (Yin, 2001). O nível de análise do estudo é organizacional, uma vez que se concentra nos aspectos de cada uma das empresas selecionadas, e a abordagem do trabalho é qualitativa, não pretendendo a generalização, e sim a interpretação de uma realidade observada. 
Para atender o objetivo da pesquisa, primeiramente, desenvolveu-se um protocolo de análise dos dados (Yin, 2001), visando, principalmente, auxiliar na análise da relação entre estratégias e práticas de sustentabilidade nas suas várias dimensões - social, ambiental e econômica - e a adoção de TI Verde. Assim, elencaram-se alguns itens relacionados a cada dimensão. Na social, apresentaram-se aspectos como os relacionados ao capital humano da empresa, ao envolvimento com a comunidade, à transparência e à postura ética; na ambiental, à proteção do meio ambiente, à utilização de recursos renováveis e à gestão de resíduos; na econômica, ao resultado econômico, à redução de custos e à eficiência energética (Brooks et al., 2010; Elkington, 2001; Slaper \& Hall, 2011). Posteriormente, elaboraram-se questões para compor os instrumentos de coleta de dados, as quais emergiram da revisão teórica sobre sustentabilidade e TI Verde (Jenkin, Webster, \& McShane, 2011; Lunardi, Frio, \& Brum, 2011; Molla et al., 2008). Desenvolveu-se um roteiro semiestruturado para a realização de entrevistas com os gestores responsáveis pela área de TI das empresas investigadas, contendo questões sobre as características da empresa e do respondente, além de 11 perguntas para levantar dados sobre os fatores motivadores das ações verdes, a relação da TI Verde com as estratégias da empresa, as práticas adotadas, os fatores críticos de sucesso, os benefícios e as dificuldades percebidas (Anexo). Adicionalmente, concebeu-se um questionário estruturado com questões fechadas a ser respondido por usuários de TI (instrumento não utilizado nas análises realizadas neste artigo), além de outros métodos para a coleta de dados secundários, detalhados mais à frente.

Na etapa de seleção dos casos, contatou-se uma empresa de consultoria na área de Gestão Ambiental com atuação em vários municípios do sul do Rio Grande do Sul, com o intuito de identificar empresas representativas em seus setores de atuação, que estivessem implementando há algum tempo mudanças na área de TI, decorrentes de programas de melhoria em Gestão Ambiental. A partir das indicações recebidas, os pesquisadores optaram por analisar três companhias de diferentes setores de atuação. Estas empresas foram selecionadas, primeiramente, por estarem em estágios avançados quanto à adoção de práticas sustentáveis aplicadas à área de TI (todas elas há mais de dois anos inseridas neste movimento) e, posteriormente, pelo seu porte. Estabeleceu-se a definição desses critérios de inclusão com a expectativa de obter maior diversidade de dados empíricos, propiciando maior riqueza à análise. É válido observar que até o início do estudo não havia qualquer envolvimento ou vínculo entre os pesquisadores e as empresas selecionadas.

O primeiro contato com estas três empresas se deu por e-mail, através de uma manifestação de interesse na realização de entrevistas com seus respectivos gestores da área de TI, bem como o encaminhamento da apresentação da proposta de pesquisa. Após o retorno dos e-mails e agendamento prévio com os gestores, procedeu-se à etapa de coleta de dados. As entrevistas foram realizadas pessoalmente nas sedes administrativas das empresas e tiveram duração aproximada de uma hora, sendo registradas por meio de gravação de áudio e, em seguida, transcritas. Adicionalmente, foram aplicados métodos secundários de coleta de dados, que consistiram em observação do ambiente da empresa para conhecimento de equipamentos, e consulta ao site corporativo e a documentos das empresas para complementar as informações cedidas nas entrevistas pelos gestores. A Tabela 1 apresenta o perfil dos entrevistados quando da coleta de dados. 
Tabela 1

Características dos Entrevistados

\begin{tabular}{|c|c|c|c|c|c|}
\hline Entrevistado & Empresa & $\begin{array}{l}\text { Tempo de } \\
\text { Empresa }\end{array}$ & Cargo & Formação & Idade \\
\hline Gestor 1 & Empresa A & 3 anos & $\begin{array}{c}\text { Gerente } \\
\text { Administrativo }\end{array}$ & $\begin{array}{l}\text { Graduação em Administração e } \\
\text { Especialização em Sistemas de } \\
\text { Informação }\end{array}$ & 30 \\
\hline Gestor 2 & Empresa B & 2 anos & $\begin{array}{c}\text { Analista de } \\
\text { Sistemas Pleno }\end{array}$ & Engenharia da Computação & 29 \\
\hline Gestor 3 & Empresa C & 3 anos & $\begin{array}{l}\text { Coordenador de } \\
\text { Sistemas }\end{array}$ & $\begin{array}{c}\text { Graduação em Análise de } \\
\text { Sistemas, MBA em Gestão } \\
\text { Empresarial e MBA em Gestão } \\
\text { de Projetos }\end{array}$ & 35 \\
\hline
\end{tabular}

Para tratamento e análise dos dados, utilizou-se a técnica de análise categorial, sendo as categorias de análise identificadas por meio de procedimentos interpretativos (Bardin, 2009). É válido observar que se percebeu a necessidade de não seguir a recomendação da exclusão mútua ao se analisarem as práticas de TI Verde frente às dimensões da sustentabilidade. Assim, na discussão dos resultados, certas práticas estão classificadas em duas ou mais categorias, destacando intersecções por meio de um diagrama de Venn, que proporcionou melhor compreensão do fenômeno investigado.

\section{Resultados}

Para a análise e interpretação dos dados, consideraram-se essencialmente os motivos de adoção, as práticas implantadas, os benefícios alcançados e as dificuldades enfrentadas, buscando compreender como esses diferentes componentes influenciam a forma como as organizações têm abordado a sustentabilidade na área de TI. A seguir, apresentam-se os três casos, contendo trechos das respostas dos gestores a título de ilustração. Na seção subsequente, discutem-se os resultados.

\section{Empresa A}

A empresa A é uma empresa de médio porte que atua no segmento de varejo de medicamentos e emprega 87 funcionários diretos em suas oito (8) lojas. A empresa faz parte de uma rede de farmácias que busca o sistema de cooperação como forma de competir frente às grandes concorrentes do setor, visando obter poder de barganha com fornecedores e oferecer preços competitivos aos consumidores.

Após um estudo de processos da empresa, a equipe de TI verificou a necessidade de implantar novas tecnologias que permitissem reduzir os custos operacionais e proporcionar maior agilidade nos processos. As práticas de TI Verde consideradas mais adequadas para a empresa foram adotadas em decorrência de problemas como: ineficiência nos processos internos e externos, elevada depreciação do seu parque tecnológico, alto custo e tempo desperdiçado na manutenção dos equipamentos de informática, elevado índice de descarte de materiais recicláveis e um alto consumo de energia. Para atender às necessidades da empresa, práticas foram adotadas para sanar problemas operacionais cotidianos, atender à legislação, tornar os processos mais ágeis e economizar recursos da organização. Revelam, principalmente, a busca por práticas que priorizem resultados em termos de ecoeficiência (Brooks et al. 2010), e motivadas por locus interno e questões econômicas que reflitam tanto no desempenho operacional quanto financeiro da empresa, conforme assinalado por Molla e Abareshi (2012) e Elkington (2001). Quanto à economia de energia, o gestor destaca algumas ações e reduções alcançadas. No dizer do gestor: 
“a gente está trabalhando, hoje, principalmente com a virtualização de máquinas. A gente compra uma máquina e as estações para virtualizar. Então, assim, a gente acaba usando uma máquina como servidora e consegue elencar até cinco máquinas que funcionam tranquilo. Máquinas que têm o consumo de energia bem reduzido, chega a ser só 5 watts... o consumo é bem mais baixo comparado com uma máquina normal e a gente consegue aproveitar o processamento dela ao máximo" (Gestor 1).

Dentre as práticas adotadas pela empresa A, estão a virtualização de computadores, a modernização do parque tecnológico (com substituição de monitores CRT por monitores LCD e aquisição de equipamentos mais eficientes), a digitalização de documentos, o uso de MSN coorporativo (com autorização da área de TI), a utilização de ecofonte nas impressões, a proteção de tela em períodos de inatividade, o controle de impressões e a impressão consciente, a utilização de tecnologia VoIP e central telefônica, a reutilização de papel, e o descarte correto de equipamentos eletrônicos e produtos a serem reciclados. A empresa também passou a adotar mecanismos de controle que buscam acompanhar, especialmente, o número de impressões e a utilização de cartuchos e tôneres, percebido em trechos de falas como o seguinte:

"A gente tem um acompanhamento também, tem praticamente uma estatística, uma média de impressões por cartucho. Cada vez que começa a fugir muito daquele valor padrão, a gente entra em contato com a loja, vê o que está acontecendo. Às vezes, pode ser um problema de configuração da máquina" (Gestor 1).

Ao implantar práticas mais simples, como reutilização de papel e utilização de tecnologia VoIP para comunicação, a empresa reduziu seus custos com telefonia e consumo de papel. Além disso, a introdução dessas medidas fez com que a organização, como um todo, pudesse caminhar rumo a uma nova postura organizacional, uma postura mais sustentável, de modo a preservar diferentes recursos de maneira consciente. Isso traz à empresa benefícios tangíveis em um horizonte mais a longo prazo, visto que os agentes multiplicadores das ideias e dos comportamentos são os indivíduos e o comportamento sustentável vai se tornando, ao longo do tempo, um fator comum entre todos os membros da organização. Tais questões relacionadas à sustentabilidade e economia de recursos, segundo o gestor de TI da empresa, é uma preocupação que antes não existia na organização, mas a sustentabilidade empresarial passou a ser um objetivo corporativo. Desse modo, percebe-se, além do ganho econômico, o benefício ambiental - ecoequidade, nas palavras de Brooks et al. (2010). No que se refere à motivação, demonstra origem interna e foco sociopolítico, estabelecida na relação que a organização e seus colaboradores têm com o meio ambiente, provenientes de crenças e valores para outros fins que não o econômico - ecoeficácia, segundo Molla e Abaresh (2012). Ademais, percebe-se um movimento proativo da organização em relação às práticas sustentáveis, ampliando o conceito de proatividade relacionado puramente à dimensão ambiental, uma vez que se inserem aspectos econômicos e sociais em sua concepção, integrando, dessa forma, as dimensões de sustentabilidade propostas por Elkington (2001). Abaixo, o gestor relata trechos dessas constatações:

"Em termos de benefícios internos, como toda empresa, a gente visa lucro, a economia, a melhoria dos processos. Tem processos que a gente usa frente e verso da folha, usa uma fonte mais econômica, e isso acaba criando uma consciência coletiva na empresa, do zelo, e a gente usa melhor o material que a empresa disponibiliza" (Gestor 1).

A utilização de ecofonte nas impressões reduz o consumo de carbono nas impressoras, polui menos e é mais econômica porque aumenta o ciclo de vida útil do tôner utilizado pela empresa. A digitalização de documentos elimina, aos poucos, os arquivos em papel que ocupam espaço e demandam manutenção, passando a ser armazenados na nuvem, através do processo de virtualização. A virtualização também é uma vantagem para a organização porque permite o acesso aos dados de diversas unidades operacionais, ou seja, os dados podem ser acessados a qualquer momento e em qualquer loja, o que os arquivos físicos não permitem. A proteção de tela é um recurso próprio das máquinas que permite economia de energia durante os períodos de inatividade, assim como a substituição de monitores CRT por LCD. A tecnologia VoIP e o uso de centrais telefônicas reduzem o custo com ligações internas e externas, e possibilitam a redução das faturas de telefone e da demora no tráfego de dados (reduzindo os custos com ligações em até 70\%). O MSN coorporativo, por sua vez, permite o envio de mensagens instantâneas de caráter interno e externo, acelerando o processo de comunicação e eliminando custos com deslocamento entre as lojas da empresa. 
Os principais benefícios percebidos com a adoção dessas práticas foram: redução do consumo de energia, papel e transporte; redução dos custos de telefonia; maior segurança na tecnologia atual; e a conscientização ambiental por parte dos funcionários, o que faz com que sejam levadas adiante as iniciativas propostas pela administração. O gestor acrescenta a importância de fazer um planejamento demonstrando claramente o retorno do investimento:

\footnotetext{
"Nossos gestores acharam o custo do investimento muito elevado, mas nós já fomos com um plano de ações traçado e com metas, apresentando o que isso vai trazer de retorno e benefícios, o que isso vai melhorar para a empresa" (Gestor 1).
}

As principais dificuldades elencadas pela empresa durante a implantação dessas práticas foram: a necessidade de planejamento das necessidades; a definição de objetivos e instrumentos de controle para mensurar ganhos e benefícios; a necessidade de elaborar um projeto de infraestrutura tecnológica que atenda às necessidades da empresa, pensando também nas questões de sustentabilidade; o aceite da alta administração para colocar o projeto em prática; o custo de mudança que demanda tempo de adaptação dos funcionários para que as medidas possam ser implantadas, especialmente no caso das práticas mais radicais; e o alto investimento para substituir o parque de máquinas e contratar serviços de consultoria especializadas que pudessem auxiliar no mapeamento e na implementação dessas práticas. Entre as práticas mais difíceis de serem implantadas, o entrevistado destacou aquelas que dependem da consciência dos colaboradores e desenvolvimento de novos hábitos, expondo que:

\footnotetext{
“As práticas mais difíceis envolvem as pessoas. Gerar a consciência de imprimir frente e verso, usar uma fonte mais econômica, desligar o computador ao sair do trabalho, mas acho que hoje a gente já está conseguindo andar bem com isso. Mas acho que o maior desafio é fazer o usuário perceber a importância e adotar essas medidas. E um pouquinho, também, o custo que as coisas têm: o acesso a novas tecnologias ainda é muito restrito nessa área" (Gestor 1).
}

Além disso, constatou-se que a empresa não analisa requisitos legais e ambientais dos seus fornecedores de TI para verificar se estes possuem alguma certificação ambiental, selo verde ou garantia de que atuam de forma ambientalmente correta. $\mathrm{O}$ gestor salienta apenas que os aspectos observados quando da aquisição dos equipamentos são a garantia de mercado, a reputação do produto e do fabricante, o preço do produto e, finalmente, o aspecto ambiental.

\section{Empresa B}

A empresa B é uma empresa de grande porte que atua no segmento de comércio de combustíveis e emprega cerca de 450 funcionários diretos e indiretos, em 19 postos de combustíveis espalhados pela região sul do Rio Grande do Sul. Por operar 24 horas por dia, sete dias por semana, o tempo e a energia são muito valiosos à empresa. Cada máquina que para de funcionar demanda tempo para conserto, o que causa impacto na lucratividade da empresa. A falta de energia ocasiona perda brusca no faturamento com a interrupção dos sistemas e com a paralisação das máquinas de cartões de débito e crédito, por exemplo. Além da perda de faturamento com clientes, o consumo de energia é responsável por representativa parcela das suas despesas.

Esse contexto fez com que os gestores da empresa considerassem em seu planejamento fatores como energia e tempo envolvido no processo de solução de problemas, o que levou à escolha de certas práticas de TI Verde, entendidas como mais adequadas ao ramo de atuação da organização. Similarmente ao percebido na Empresa A, a busca por ecoeficiência (Brooks et al., 2010; Molla \& Abaresh, 2012) orientou as iniciativas neste caso, destacando-se como a principal motivação para a adoção da TI Verde. Percebem-se claramente aspectos relacionados à dimensão econômica de Elkington (2001), na qual a busca por ecoeficiência promove contínuas inovações tecnológicas com foco na manutenção da lucratividade das empresas em novos contextos.

As principais práticas verdes adotadas pela empresa B na área de TI foram: a utilização de thin clients - terminais burros que operam sem a necessidade de um computador completo; a virtualização, eliminando o custo de manutenção dos arquivos físicos e permitindo ganho de espaço; a substituição do parque de máquinas por equipamentos mais eficientes, possibilitando economia de energia e espaço, 
além de redução do calor produzido pelas máquinas (minimizando outros custos indiretos, como o de refrigeração); a substituição de monitores CRT por LCD; a terceirização de impressões, reduzindo o custo de manutenção das impressoras; a reutilização de papel; a reciclagem de cartuchos; a reutilização de peças; o controle de impressões, através de um limite de cópias mensais disponibilizadas aos usuários; a doação de equipamentos inservíveis; e o descarte correto de equipamentos eletrônicos. A relação estabelecida entre redução de consumo de energia, custos e sustentabilidade pode ser observada nas seguintes palavras do gestor:

"a gente usa os thin clients, ele elimina a operação de uma CPU onde o consumo de energia é muito maior. É um micro terminal que faz acesso remoto a um servidor. Eu vejo na redução de custo de energia elétrica... Olhando essa parte da sustentabilidade, tu eliminas uma quantidade enorme de CPUs. Aqui mesmo, seriam umas 8 CPUs só na central. Se tu espalhares isso por todos os postos, que hoje são 16 em funcionamento, imagina... reduz bastante o consumo" (Gestor 2).

A empresa também tem a política de adquirir equipamentos que possuem algum tipo de certificação ambiental ou selo verde. De acordo com o entrevistado, os motivos norteadores para a adoção dessas práticas foram a pressão de fornecedores, que passaram a exigir uma postura ambientalmente correta, atendendo à demanda com produtos com selo verde, e as próprias questões de legislação (como o descarte correto de equipamentos eletroeletrônicos e o uso da nota fiscal eletrônica) e órgãos reguladores das atividades relacionadas a postos de combustíveis. Identifica-se o que Molla e Abareshi (2012) denominam como ecolegitimidade, onde a TI Verde é motivada por pressões sociais e políticas exercidas sobre a organização, e ecorresponsividade, impulsionada por oportunidades verdes como resposta a ações de concorrentes, parceiros de negócios e clientes. De tal forma, essas pressões externas, com foco sociopolítico (ecolegitimidade) ou econômico (ecorresponsividade), condicionam a organização a adotar padrões de operação que promovam ações sustentáveis no contexto onde ela está inserida, compreendendo as três dimensões propostas no modelo TBL de Elkington (2001) - social, ambiental e econômica. Conforme o gestor esclarece,

“O posto de gasolina, por obrigatoriedade, é uma das empresas que mais está dentro da parte ambiental. [Há] a necessidade da nota fiscal eletrônica e, além das práticas de TI, por obrigatoriedade, também tem toda essa questão de resíduos" (Gestor 2).

Além das providências obrigatórias, outras práticas administrativas internas (como a redução de papel, o menor tempo e custo exigido na manutenção de equipamentos, a reciclagem de tôner e a economia de energia), sem qualquer relação com os órgãos fiscalizadores de meio ambiente, foram introduzidas para economizar recursos financeiros, aumentar o ciclo de vida dos equipamentos de TI e o espaço físico da empresa, contribuindo, dessa forma, com o desenvolvimento de uma conduta organizacional mais sustentável.

Dentre as principais dificuldades identificadas na adoção dessas práticas, estão os altos investimentos necessários, a resistência à mudança de hábitos e de comportamentos por parte dos funcionários, e a dificuldade de mensurar os seus resultados. Como o gestor declara:

"A gente não considerou difícil implementar a mudança com as impressoras, mas a parte dos servidores e dos thin clients, sim. A grande dificuldade que eu vi foi da parte das pessoas. Tinha uma resistência: alguns tinham o hábito da CPU, de arquivos, de mídias, acesso à internet que antes era liberado e agora não é mais. As pessoas não querem aprender o sistema novo para não perder os hábitos. Tivemos um investimento muito alto em servidores, na parte de rede, mas fomos facilmente convencidos porque a gente tinha a dificuldade da estrutura. Então a gente tinha uma dificuldade operacional e um problema de custo ao mesmo tempo. Notamos benefícios com a utilização dessas práticas, mas não mensuramos os resultados" (Gestor 2).

Em compensação, consideram que os benefícios percebidos foram superiores às dificuldades. Destacam-se entre os principais: o baixo índice de manutenção das máquinas, o que diminui o downtime e o tempo útil despendido na realização de manutenções; o menor custo na aquisição de produtos, visto que os thin clients são mais baratos e econômicos que os PCs convencionais; a reciclagem de peças, o que permite economia financeira e aumenta o ciclo de vida dos equipamentos; a maior segurança dos dados, obtida com a virtualização; os ganhos de espaço físico, através da virtualização de servidores e 
dos equipamentos mais eficientes e modernos; economia de recursos e materiais; eficiência operacional; e redução do consumo de energia.

\section{Empresa C}

A empresa C, também classificada como de grande porte, é um terminal de contêineres que atua no segmento de logística portuária no setor de importação e exportação, empregando cerca de 1.000 funcionários diretos. A organização possui intensos procedimentos operacionais que demandam amplo espaço físico, alto consumo de energia e grande número de computadores, existindo, inclusive, funcionários que possuem mais de um computador. Por atuar no ramo de comércio exterior, a quantidade de dados transacionados é muito grande e demanda certa agilidade no processamento das informações.

O entrevistado considera que muitas das ações sustentáveis no mundo corporativo são consequência de um modismo. No entanto, ele afirma entender que tais ações reduzem o impacto ao meio ambiente. Argumenta, também, ter tomado conhecimento acerca das práticas de TI Verde através de benchmarking, junto a outras empresas de segmentos distintos. Diferentemente da motivação externa com foco sociopolítico (ecolegitimidade), a oriunda de modismos e conhecimento das melhores práticas no mercado tem seu foco em benefícios econômicos (ecorresponsividade) (Molla \& Abareshi, 2012), podendo levar a organização a uma posição competitiva mais privilegiada, seja reduzindo custos (Kim $\&$ Ko, 2010), seja tendo acesso preferencial a mercados que melhor recompensem empresas verdes (Melville, 2010; Molla \& Abareshi, 2012).

Além da influência da legislação (ecolegitimidade) quanto à obrigatoriedade da emissão de notas fiscais eletrônicas, discutida mais adiante, destacaram-se como principais motivos de adoção de práticas de TI Verde na empresa $\mathrm{C}$ a ecoeficiência, a ecorresponsividade e a ecoeficácia (Molla \& Abareshi, 2012). Tais constatações podem ser observadas na seguinte fala do gestor:

"Os principais motivos que nos levaram a investir nesse tipo de tecnologia foram principalmente o custo, depois a imagem, como secundário... E pela empresa ter um compromisso com o Meio Ambiente, o grupo faz parte do pacto global com a sustentabilidade, que busca promover a sociedade e as futuras gerações" (Gestor 3).

Desse modo, os elementos que influenciam a adoção de práticas de TI Verde pela organização estão diretamente relacionados às dimensões do TBL, proposto por Elkington (2001), como forma de tentar alcançar a sustentabilidade empresarial, equilibrando preocupações e iniciativas nas dimensões econômica, ambiental e social. A empresa desenvolve práticas verdes em diversas áreas funcionais, sendo as de TI as seguintes: o controle de impressões, através do controle por senha de usuário (o que limita o número de impressões por pessoa na empresa, evitando o desperdício de papel, tôner e consumo de energia); a criação do depósito de TI, organizando materiais a serem doados, descartados, reciclados ou reutilizados em futuras manutenções; a atualização do parque tecnológico (equipamentos mais eficientes energeticamente e uso de monitores LCD); a terceirização de impressoras; a presença de uma política de sustentabilidade; a digitalização de documentos; e o projeto piloto de virtualização e terceirização de servidores, não sendo ainda efetivo, devido a uma grande quantidade de dados a serem migrados, percebido ainda como um alto custo de troca. Como forma de promover a responsabilidade socioambiental, a empresa possui ainda uma política interna de educação ambiental.

Com a adoção de práticas de TI Verde, os principais resultados percebidos foram: a redução dos gastos e quantidade de insumos como papel, tôner e energia; a redução da utilização de papel com a informatização do sistema de notas fiscais (danfe) e a atualização do parque de máquinas, com a troca de $100 \%$ dos monitores CRT por LCD e aquisição de novos equipamentos, o que reduziu consideravelmente a quantidade de energia consumida. Isto pode ser verificado na seguinte opinião, extraída da fala do gestor:

"Os resultados que a gente percebeu com a adoção dessas práticas foram principalmente a redução dos gastos e quantidade de recursos que se consumia, como: papel, tôner e energia, redução da utilização de papel com a informatização do sistema de notas fiscais (o danfe)... Também atualizamos nosso parque de máquinas trocando $100 \%$ dos monitores; isso reduziu bruscamente a quantidade de energia que era 
consumida e, por outro lado, também aumentou o espaço disponível. Com isso, conseguimos ter melhores condições de trabalho e novas pessoas nas unidades operacionais. Implementando tudo isso, principalmente substituindo as máquinas, doamos muitos PCs para instituições de caridade e escolas do município" (Gestor 3).

Com a emissão das notas fiscais eletrônicas, há a diminuição do consumo de três vias de carbono por nota fiscal, o que economiza cerca de 9.000 folhas por mês, somente com a adoção deste procedimento. Além da diminuição do consumo de papel, há a redução do custo com a manutenção de impressoras, tôner, energia, ruído e calor. Nesse sentido, a empresa também substituiu os manifestos impressos, que são documentos que contêm entre 400 e 500 folhas e que acompanham a carga para discriminar o conteúdo de cada contêiner, pela sua digitalização. Estes documentos eram impressos e as cópias em papel eram armazenadas em um depósito, ocupando lugar e tomando tempo de trabalho dos profissionais da área de TI. Com essas medidas tomadas pela empresa, houve ampliação do espaço físico disponível, o que permitiu oferecer melhores condições de trabalho aos funcionários e, ainda, incluir novas pessoas nos setores operacionais. Além disso, passaram a realizar de modo sistemático a doação de PCs usados, porém ainda utilizáveis, para instituições de caridade e escolas da cidade, o que evidencia o impacto da TI Verde no aspecto social da sustentabilidade (Brooks et al., 2010).

Ao iniciar o processo de adoção dessas práticas, a empresa teve dificuldades relacionadas especialmente à cultura organizacional bastante enrijecida. De acordo com o gestor entrevistado, os funcionários estavam apegados ao papel e à leitura em mãos, sendo muito resistentes à mudança de hábitos, conforme o gestor expressa:

“A empresa possui mais de 1000 funcionários diretos e mais os terceirizados, então, é difícil ter uma mudança brusca no comportamento. Mas estão caminhando para isso... A média de idade na empresa está entre 25 e 35 anos; com a redução da idade dos profissionais hoje, a cultura está mudando um pouco, já que essa geração já tem alguns aspectos ambientais incorporados. A cultura das pessoas ainda não é socialmente responsável, não existe uma consciência de sair da sala e desligar os splits, colocar o PC em modo espera e, até mesmo, desligá-lo antes de ir embora" (Gestor 3).

Ainda, conforme o entrevistado, durante o processo de mudança, foi possível perceber que quando a situação é influenciada por uma questão legal ou estimulada pelas chefias, as iniciativas de TI Verde são efetivadas mais rapidamente. Em relação às barreiras, foram apontadas: a dificuldade na elaboração de um planejamento de TI Verde eficaz, de forma a mensurar e avaliar os impactos e resultados obtidos; e a escolha dos equipamentos e avaliação dos seus fabricantes. As decisões de compra de equipamentos de informática são repassadas de cima para baixo, não levando em consideração os requisitos ambientais dos produtos. Observam-se apenas as garantias do produto, reputação do fornecedor, da marca e do produto.

Após o relato dos três casos, apresenta-se uma síntese dos resultados na Tabela 2. Os resultados indicam que as principais práticas de TI Verde envolvem: controle de recursos, terceirização de servidores e impressoras, virtualização, substituição de equipamentos, coleta seletiva e descarte correto. Além disso, revelam que apesar de alguns desses investimentos serem altos, apresentam um retorno financeiro rápido, especialmente se mensurada a economia de recursos potencializada às organizações (incluindo-se a possibilidade de multas e penalidades cobradas pelo não cumprimento de exigências legais associadas a essas questões). 
Tabela 2

Síntese dos Resultados

\begin{tabular}{|c|c|c|c|}
\hline & Empresa A & Empresa B & Empresa C \\
\hline \multirow[t]{15}{*}{ Práticas } & Virtualização & Virtualização & Virtualização \\
\hline & Monitores LCD & Monitores LCD & Monitores LCD \\
\hline & Digitalização de documentos & Controle de impressões & Digitalização de documentos \\
\hline & MSN coorporativo & Reutilização de papel & Controle de impressões \\
\hline & Ecofonte & Thin Clients & Terceirização de impressões \\
\hline & Proteção de tela & Terceirização de impressões & Equipamentos mais eficientes \\
\hline & Controle de impressões & Equipamentos mais eficientes & Reciclagem de \\
\hline & VoIP/central de ligações & Reciclagem de & peças/cartuchos \\
\hline & Reutilização de papel & peças/cartuchos & Doação de equipamentos \\
\hline & Equipamentos mais eficientes & Doação de equipamentos & Descarte correto \\
\hline & Reciclagem de & Descarte correto & Reutilização de peças \\
\hline & peças/cartuchos & Reutilização de peças & Terceirização de servidores \\
\hline & Descarte correto & Nota fiscal eletrônica & Nota fiscal eletrônica \\
\hline & Ferramentas de controle de & Fornecedores com selo verde & Política de sustentabilidade \\
\hline & consumo & & $\begin{array}{l}\text { Ferramentas de controle de } \\
\text { consumo }\end{array}$ \\
\hline \multirow[t]{9}{*}{ Motivos } & Legislação & Legislação (nota fiscal & \multirow{9}{*}{$\begin{array}{l}\text { Legislação } \\
\text { Redução de custos } \\
\text { Imagem institucional } \\
\text { Benchmarking } \\
\text { Política da empresa }\end{array}$} \\
\hline & Eficiência nos processos & eletrôn & \\
\hline & Redução de custos & Pressão dos fornecedores & \\
\hline & Elevada depreciação do parque & Elevados custos de & \\
\hline & tecnológico & & \\
\hline & $\begin{array}{l}\text { Elevados custos de } \\
\text { manutenção }\end{array}$ & $\begin{array}{l}\text { Processos legais para operação } \\
\text { do negócio }\end{array}$ & \\
\hline & Elevado consumo de energia & Elevado índice de descarte & \\
\hline & Elevado índice de descarte & $\begin{array}{l}\text { Aumentar a vida útil dos } \\
\text { equipamentos de TI }\end{array}$ & \\
\hline & & Aumentar espaço físico & \\
\hline \multirow[t]{9}{*}{ Benefícios } & Menor consumo de energia & Menor custo de manutenção & \multirow{9}{*}{$\begin{array}{l}\text { Menor custo de manutenção } \\
\text { Menor consumo de energia } \\
\text { Redução do consumo de papel } \\
\text { e tôner } \\
\text { Ganho de espaço físico } \\
\text { Melhor ambiente } \\
\text { organizacional }\end{array}$} \\
\hline & Redução do consumo de papel & Menor custo de aquisição & \\
\hline & e tôner & Maior segurança & \\
\hline & Redução de gastos com & Ganho de espaço físico & \\
\hline & & Menor consumo de energia & \\
\hline & $\begin{array}{l}\text { Redução dos custos de } \\
\text { telefonia }\end{array}$ & $\begin{array}{l}\text { Redução do consumo de papel } \\
\text { e tôner }\end{array}$ & \\
\hline & Maior segurança & umento do ciclo de vida dos & \\
\hline & Maior consciência ambiental & produtos de TI & \\
\hline & Eficiência operacional & Eficiência operacional & \\
\hline \multirow[t]{7}{*}{ Dificuldades } & Alto investimento inicial & Alto investimento inicial & Resistência à mudança \\
\hline & Resistência à mudança & \multirow[t]{6}{*}{ Resistência à mudança } & Desconhecimento da \\
\hline & Aceite da alta Administração & & tecnologia e dificuldade de \\
\hline & Planejamento eficaz da adoção & & \\
\hline & da TI Verde & & \multirow{3}{*}{$\begin{array}{l}\text { Planejamento eficaz da adoção } \\
\text { da TI Verde } \\
\text { Avaliar objetivamente os }\end{array}$} \\
\hline & Avaliar objetivamente os & & \\
\hline & & & \\
\hline
\end{tabular}




\section{Discussão dos Resultados}

Após a apresentação dos casos analisados, discutem-se os resultados com base em três constatações. A primeira sinaliza a necessidade de as organizações considerarem a inclusão de fatores relacionados às exigências legais nos processos de tomada de decisão, além dos fatores presentes nas dimensões econômica, ambiental e social; a segunda conclui que práticas de algumas dimensões são consideradas mais influentes que de outras; e a terceira indica que as organizações passarão a adotar práticas verdes na gestão da TI e de outras áreas, a partir do momento que identificarem benefícios financeiros e operacionais com a sua adoção.

Ao se analisar as práticas de TI Verde elencadas na pesquisa, relacionando-as às dimensões social, ambiental e econômica - oriundas do entendimento de sustentabilidade oferecido por Elkington (2001), percebeu-se a necessidade de se acrescentar uma quarta dimensão, a legal, uma vez que a análise permitiu identificar, ainda que de forma embrionária, a existência de importantes barreiras ou exigências legais para a liberação de algumas operações das empresas. Em determinadas situações, as organizações governamentais interferem no processo de adoção de práticas de TI Verde. No momento em que são criadas leis e regulamentações para determinados setores, as organizações atingidas se sujeitam a buscar competitividade e legitimidade por meio de posturas mais responsáveis e ambientalmente corretas, ao passo que também contribuem para uma mudança no perfil dos consumidores. Estes, por sua vez, passam a valorizar posturas mais sustentáveis e adotar comportamentos socialmente desejáveis. É válido observar que, no Brasil, tem-se a lei que institui a Política Nacional de Resíduos Sólidos (Lei n. 12.305, 2010). Entre outras regulamentações, obriga fabricantes, importadores, distribuidores e comerciantes de produtos eletroeletrônicos e seus componentes a estruturar e implementar sistemas de logística reversa, mediante retorno dos produtos após o uso pelo consumidor.

Assim, a dimensão legal foi incluída neste estudo como um fator a ser observado pelas empresas no processo de definição de políticas e estratégias, com vistas a se manterem ambientalmente corretas. Um exemplo diretamente relacionado à TI é a exigência da adoção da nota fiscal eletrônica, presente nas dimensões legal, ambiental e econômica. No entanto, é válido salientar que ainda há pouca regulamentação relacionada às operações ambientalmente corretas das organizações, observado pelo reduzido número de práticas que estão relacionadas a esta quarta dimensão.

A fim de se ilustrar as intersecções das quatro dimensões, posicionando-se as práticas identificadas nos três casos, desenvolveu-se um diagrama de Venn (Figura 2). Destaca-se que este diagrama utilizando quatro elementos não possibilita o posicionamento de práticas com as seguintes combinações: intersecção apenas entre as dimensões legal e ambiental ou entre as dimensões econômica e social; porém, tal restrição não inviabilizou a análise da ilustração, uma vez que as práticas identificadas nos casos analisados não ocorreram nas referidas situações. É válido observar que, embora os motivos que influenciam a adoção da TI Verde possam ser categorizados (Molla \& Abareshi, 2012), conforme apresentado no referencial teórico, a análise dos casos revelou que as práticas nem sempre estão associadas a uma única categoria de motivação. Em certos casos, implanta-se uma prática visando à sustentabilidade em consequência de pressões, tanto externas como internas, bem como de interesses que mesclam objetivos econômicos, ambientais, sociais e legais, tornando o diagrama de Venn uma ferramenta apropriada para demonstrar o posicionamento das práticas nas intersecções estabelecidas. 
1. Virtualização,

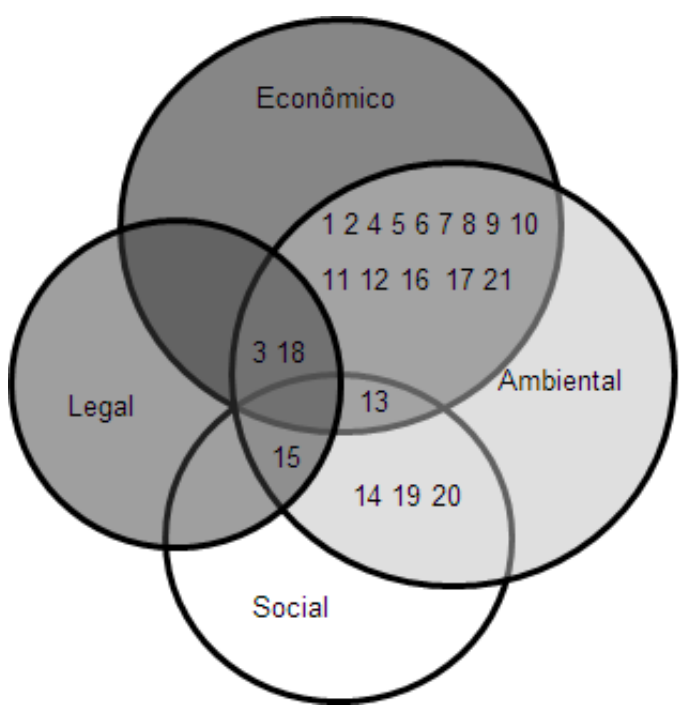

2. Monitores LCD,

3. Digitalização de documentos,

4. MSN coorporativo,

5. Ecofonte,

6. Proteção de tela,

7. Controle de impressões,

8. VoIP/central de ligações,

9. Reutilização de papel,

10. Thin Clients,

11. Terceirização de impressões,

12. Equipamentos mais eficientes,

13. Reciclagem de peças/cartuchos,

14. Doação de equipamentos,

15. Descarte correto,

16. Reutilização de peças,

17. Terceirização de servidores,

18. Nota fiscal eletrônica,

19. Fornecedores com selo verde,

20. Política de sustentabilidade,

21. Ferramentas de controle de consumo.

Figura 2. Práticas de TI Verde associadas às Dimensões Econômica, Ambiental, Social e Legal

No contexto da realização dessa pesquisa, verificou-se que todas as empresas analisadas destacaram preocupações com as quatro dimensões propostas de forma distinta. Umas estão mais preocupadas do que outras com a dimensão ambiental devido às suas atividades operacionais. Empresas que detêm maior quantidade de recursos aplicados na informatização de seus dados tendem a ter essa preocupação mais acentuada com a dimensão financeira. Pode-se perceber que as dimensões econômica e legal são aquelas que mais influenciam ou motivam a adoção de práticas de TI Verde. As dimensões social e ambiental, neste estudo, mostraram-se como sendo as dimensões que possuem menor peso no processo de tomada de decisão - especialmente porque não são obrigatórias e trazem pequenos benefícios tangíveis no curto prazo. Exemplos citados foram a presença de uma política de sustentabilidade, a seleção de fornecedores ambientalmente responsáveis e a doação de equipamentos eletroeletrônicos sem serventia para a empresa.

Um estudo realizado pela Symantec sobre TI Verde, onde foram entrevistados 1052 executivos em diferentes países, entre eles, Brasil, Estados Unidos, França, China e Japão, mostrou que cerca de $51 \%$ dos executivos de TI brasileiros estão preocupados com tecnologias verdes. Conforme a pesquisa, o interesse em iniciativas limpas não se dá apenas pela redução de custo, mas também por conta da crescente responsabilidade social das empresas. Observou-se, ainda, que três em cada dez entrevistados brasileiros afirmaram estar dispostos a pagar até $10 \%$ a mais em produtos mais limpos (Amaro, 2009). Nesse sentido, percebe-se que a TI Verde pode assumir diferentes papéis estratégicos na organização, exigindo uma reflexão mais ampla sobre o que acarreta a efetiva implantação de práticas de TI Verde, 
não se restringindo apenas ao descarte correto e à substituição de equipamentos ineficientes, mas também à imagem e compromisso da organização com os seus diferentes públicos envolvidos.

A Figura 3 ilustra esquematicamente a percepção dos autores sobre essa diferença de cargas entre as dimensões estudadas, interpretando especificamente os pronunciamentos referentes aos principais motivos de adoção das iniciativas de TI Verde nos casos analisados. Cabe aqui destacar que se trata de uma análise qualitativa, não havendo intenção de demonstrar qualquer medida baseada em frequências e pesos destas iniciativas na tomada de decisão.

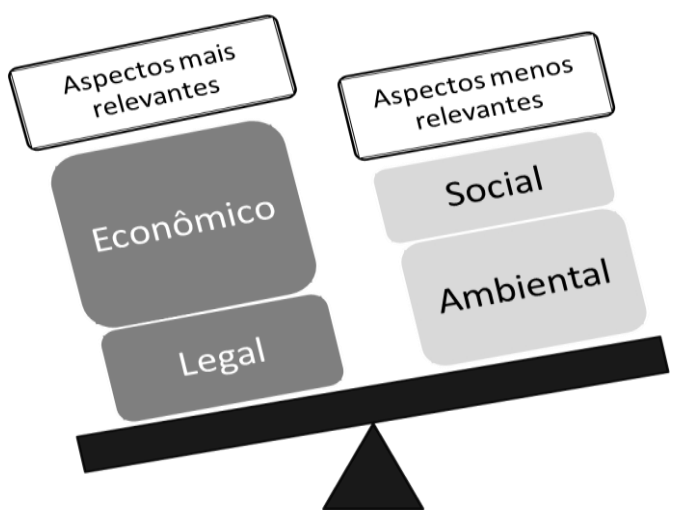

Figura 3. Peso das Dimensões Analisadas

Algumas práticas tidas como verdes, como a substituição do parque de máquinas, a utilização de datacenter verde e outras relacionadas a hardware estão elencadas entre as principais preocupações e iniciativas de mudança em prol de benefícios, primeiramente, econômicos e operacionais e, posteriormente, ambientais. Os computadores estão cada vez mais exigentes em termos de energia, devido ao seu alto poder de processamento e, para garantir bons resultados, é preciso dar atenção a essa questão. Assim, adotar práticas sustentáveis direcionadas aos datacenters - como consolidação e modernização de servidores e desktops - pode contabilizar ganhos significativos, embora exijam elevados investimentos de capital. Alguns estudos têm retratado economia no consumo de energia, através da consolidação de servidores, do uso de terminais do tipo thin client e da adoção de computadores mais eficientes e econômicos energeticamente (Murugesan, 2008, 2010). Ainda assim, a necessidade de um alto investimento financeiro para adquirir algumas dessas tecnologias verdes tem inibido ou surgido como uma grande barreira para que um maior número de empresas passe a utilizar essas tecnologias, mesmo que possa resultar em ganhos econômicos.

A dimensão econômica em questão envolve a redução de custos, normalmente através da economia de recursos como: energia, tôner, papel, transporte, telefonia, hardware e outros recursos materiais necessários para o desenvolvimento das atividades, substituindo-os, quando necessário, por outros mais econômicos e mais ambientalmente corretos, que degradem menos o meio ambiente e reflitam uma imagem positiva da empresa, aos olhos do público interno e externo. Algumas práticas mais voltadas para a dimensão econômica foram mais efetivas em algumas empresas com atividades de monitoramento, busca e atualização de conhecimentos acerca do que está disponível no mercado para substituição de hardwares e softwares, aumentando a eficiência operacional e energética, minimizando custos e, inclusive, aumentando receitas, geralmente por meio da comercialização de resíduos.

Foi possível constatar que as três empresas analisadas aderiram e mudaram comportamentos e procedimentos internos para estar de acordo com as normas e legislações vigentes acerca do meio ambiente, enfatizadas pela dimensão legal proposta neste estudo. Embora ainda exista pouca legislação diretamente voltada à TI Verde, outras regulamentações associadas à TI trazem como consequência impactos positivos na dimensão ambiental - como a eliminação de componentes nocivos nos produtos eletroeletrônicos, por exemplo. Notou-se, também, que as mudanças ocorrem mais rapidamente quando as situações são impostas, o que obriga empresas e funcionários a corrigirem ações e posturas que não estiverem de acordo com a lei vigente. Além da legislação, que funciona como uma antecipação de possíveis conflitos ambientais, a administração superior também é responsável por estimular um 
comportamento mais correto, marcado pela busca por redução do desperdício de recursos e por incentivar a consciência ambiental que, aliada à adoção das práticas, contribui para a institucionalização das ações e iniciativas de TI Verde.

Em relação à dimensão ambiental, os gestores entrevistados parecem ponderar o impacto ambiental nas suas tomadas de decisão. Percebe-se que as empresas preferem não alterar seus layouts de processos em prol de uma mudança puramente ambiental ou, ainda, que acarrete mudança da cultura organizacional ou que englobe aspectos comportamentais dos funcionários. Posto isto, é notório que as mudanças nesta dimensão necessitam de incentivos financeiros, imposições legais ou benefícios associados à imagem institucional, isto é, que promovam outros benefícios em conjunto com uma postura mais justa em relação ao meio ambiente.

Considerando a dimensão social, verificou-se que esta é a dimensão com menor peso nas decisões dos gestores entrevistados. Normalmente, suas práticas estão vinculadas à dimensão ambiental. Ao se preocupar com a preservação do meio ambiente e dos recursos não renováveis, contribui-se de maneira benéfica para a qualidade de vida das pessoas, preservando a equidade entre as gerações, representando, assim, o aspecto social das práticas. Uma prática que se mostrou comum entre as empresas foi a doação de equipamentos obsoletos - geralmente repassados a escolas e associações comunitárias - que, embora sejam considerados inservíveis por suas empresas, estão em bom estado de conservação e podem ser utilizados por outras instituições. Essa prática tem sido utilizada por diferentes organizações públicas e privadas. No caso de instituições públicas, o descarte visando à doação vem sendo intermediado através do Programa Computadores para Inclusão, da Secretaria de Logística e Tecnologia da Informação (SLTI), vinculada ao Ministério do Planejamento (Santos, Nascimento, \& Neutzling, 2014). Na iniciativa privada, encontram-se projetos de extensão universitária, como o do Centro Universitário Ritter dos Reis (UniRitter), que realiza a doação de equipamentos que ainda funcionam ou que podem funcionar, com alguns reparos, para diversas escolas de comunidades carentes e instituições beneficentes (Siqueira \& Machado, 2013).

É válido destacar, ainda, que a preocupação em aumentar a vida útil dos equipamentos, além de ser uma preocupação econômica de redução de custo com trocas e manutenções, também é uma preocupação ambiental e social, pois ao reduzir, por exemplo, a geração de resíduos, muitas vezes tóxicos, reduz-se a contaminação e a poluição do solo, da água e do ar, repercutindo na qualidade de vida da sociedade.

Ademais, indica-se que a adoção das práticas verdes na área de TI ocorre, sobretudo, quando são identificados benefícios financeiros e operacionais associados à sua adoção. Nesse sentido, o estudo mostra que os benefícios na dimensão ambiental aparecem como uma consequência positiva das mudanças provocadas em função de aspectos econômicos, como se o impacto no ambiente significasse um efeito colateral, paralelo e igualmente positivo. Práticas como a substituição do parque de máquinas por equipamentos mais eficientes energeticamente e dos monitores CRT por LCD, por exemplo, que proporcionam economia de energia, espaço e, consequentemente, custos, trazem como ganhos ambientais o fato de poluírem menos e serem equipamentos com vida útil maior. Essas questões têm afetado, inclusive, grandes empresas de TI, como a Microsoft, que a cada nova versão do Windows apresenta uma série de novos melhoramentos no que se refere ao consumo e uso eficiente de energia dos equipamentos, proporcionando benefícios ambientais e econômicos a quem tem adquirido seus produtos (Hara, 2013).

Ao se deixar de examinar as iniciativas apenas em um corte transversal e passar para uma perspectiva longitudinal, observando-se a dinâmica organizacional e da sociedade como um todo, e conectando-se iniciativas em diferentes espaços e tempos, pode-se inferir, baseado em teorias estruturacionais como a de Giddens (1984) e de Orlikowski (1992), que se está diante de um momento histórico de estruturação da sustentabilidade ambiental como uma propriedade institucional em diversos níveis organizacionais, o que torna o fenômeno mais consistente. Nessa perspectiva, as diversas práticas apontadas neste estudo e suas consequências positivas na dimensão ambiental, ainda que sejam percebidas como produtoras de efeitos colaterais positivos, auxiliarão na constituição de propriedades 
institucionais orientadas para a sustentabilidade ambiental, ocupando um plano mais relevante em futuras tomadas de decisão e no core business das empresas.

\section{Considerações Finais}

A origem desta pesquisa vem da observação de que questões relacionadas à sustentabilidade vêm se tornando cada vez mais importantes na pesquisa científica e na prática das organizações. Por meio de três estudos de caso, realizados em empresas inseridas no movimento TI Verde, buscou-se compreender melhor a relação entre estratégias de sustentabilidade e iniciativas de TI Verde nas organizações e, em particular, os diferentes motivos de adoção, as práticas aplicadas, os benefícios percebidos e as principais dificuldades enfrentadas na sua difusão.

Os resultados indicam que as ações, em sua grande maioria, enquadram-se em intersecções formadas pelas três dimensões da sustentabilidade - ambiental, social, econômica - e por uma quarta, a legal. Revelam que as dimensões econômica e legal são as que mais influenciam ou motivam a adoção de práticas de TI Verde, tendo as dimensões social e ambiental menor peso no processo de tomada de decisão. Também mostram que os benefícios na dimensão ambiental aparecem como uma consequência positiva das mudanças provocadas em função de aspectos econômicos. No que diz respeito às contribuições desta pesquisa, o estudo fornece importantes implicações teórico-empíricas, a partir das especificidades de cada caso, atingindo os objetivos propostos na pesquisa. Organizações podem capturar as informações que lhes forem pertinentes, adotando práticas conforme o seu contexto empresarial, reduzindo seus impactos ambientais e aumentando o seu desempenho.

No contexto deste estudo, o modelo estruturacional da tecnologia (Orlikowski, 1992) se mostrou apropriado para investigar o fenômeno TI Verde. Assim, à medida que certas propriedades estruturais da organização influenciam os agentes humanos na adoção da TI Verde, sua implementação reforça a sustentabilidade como propriedade institucional da organização - constatada em diferentes momentos neste estudo. No entanto, para compreender esta dinâmica, são necessárias novas investigações que aprofundem o entendimento dos processos responsáveis pela estruturação da TI Verde, observando suas condições e consequências, revelando a estrutura não como um ente estático que define restrições à ação ou limita escopos de autoridade, mas sim mostrando a dinâmica de como os esquemas interpretativos, as regulamentações e os recursos de um sistema social se relacionam e se formam, num processo definido por Giddens (1984) como dualidade da estrutura.

Como principal limitação deste estudo, aponta-se o pequeno número de empresas investigadas. Certamente, existem outras empresas que utilizam uma maior quantidade e diversidade de práticas, influenciadas pelo seu porte e ramo de atuação, não sendo, portanto, elencadas nesta pesquisa. Assim, faz-se necessário examinar estudos correlatos e realizar novas pesquisas abrangendo outras atividades empresariais e empresas de localidades diferentes das apresentadas neste artigo. Ainda assim, acreditase que este estudo traga contribuições aos executivos, no planejamento e na implantação da TI Verde em suas empresas, bem como para os pesquisadores que desejam desenvolver outras pesquisas sobre essa temática. A TI Verde pode ser uma alternativa para tornar a organização mais cautelosa nas suas rotinas, conduzindo-a para uma imagem positiva e orientando-a para o desenvolvimento sustentável. A sua adoção gera benefícios para a sociedade, além de oferecer oportunidades às organizações de introduzir à sua rotina atividades ambientalmente mais corretas.

\section{Referências}

Amaro, M. (2009). TI Verde é preocupação de executivos. Exame.com. Recuperado em 06 outubro, 2015, de http://info.abril.com.br/noticias/tecnologias-verdes/ti-verde-e-preocupacao-deexecutivos-21082009-38.shl 
Bardin, L. (2009). Análise de conteúdo (4a ed.). Lisboa: Edições 70.

Bose, R., \& Luo, X. (2012). Green IT adoption: a process management approach. International Journal of Accounting and Information Management, 20(1), 63-77. doi: 10.1108/18347641211201081

Brooks, S., Wang, X., \& Sarker, S. (2010, August). Unpacking green IT: a review of the existing literature. Proceedings of the Americas Conference on Information Systems, Lima, Peru, 16.

Colwell, S. R., \& Joshi, A. W. (2013). Corporate ecological responsiveness: antecedent effects of institutional pressure and top management commitment and their impact on organizational performance. Business Strategy and the Environment, 22(2), 73-91. doi: 10.1002/bse.732

Dyllick, T., \& Hockerts, K. (2002). Beyond the business case for corporate sustainability. Business Strategy and the Environment, 11(2), 130-141. doi: 10.1002/bse.323

Elkington, J. (2001). A teoria dos três pilares. São Paulo: Makron Books.

Elliot, S. (2011). Transdisciplinary perspectives on environmental sustainability: a resource base and framework for IT-enabled business transformation. MIS Quarterly, 35(1), 197-236.

Giddens, A. (1984). The constitution of society. Berkeley: University of California Press.

Hara, F. (2013, junho 17). Eficiência no uso de energia no Windows. TI Especialistas. Recuperado em 06 outubro, 2015 de http://www.tiespecialistas.com.br/2013/06/eficiencia-no-uso-de-energia-nowindows

Hopwood, B., Mellor, M., \& O’Brien, G. (2005). Sustainable development: mapping different approaches. Sustainable Development, 13(1), 38-52. doi: 10.1002/sd.244

Jenkin, T. A., Webster, J., \& McShane, L. (2011). An agenda for 'green' information technology and systems research. Information and Organization, 21(1), 17-40. doi: 10.1016/j.infoandorg.2010.09.003

Kim, Y., \& Ko, M. (2010, August). Identifying green IT leaders with financial and environmental performance indicators. Proceedings of the Americas Conference on Information Systems, Lima, Peru, 16.

Kiron, D., Kruschwitz, N., Haanaes, K., \& Velken, I. (2012). Sustainability nears a tipping point. MIT Sloan Management Review, 53(2), 69-74. doi: 10.1108/sd.2012.05628gaa.012

Lei $n$. 12.305 de 02 de agosto de 2010. (2010). Institui a política nacional de resíduos sólidos; altera a Lei n. 9.605, de 12 de fevereiro de 1998; e dá outras providências. Brasília, DF: Planalto, Casa Civil, DOU 3 ago. 2010.

Loss, P., Nebel, W., Gomez, J. M., Hasan, H., Watson, R. T., Brocke, J. von, Seidel, S., \& Recker, J. (2011). Green IT: a matter of business and information systems engineering?. Business \& Information systems Engineering, 3(4), 245-252. doi: 10.1007/s12599-011-0165-5

Lunardi, G., Frio, R., \& Brum, M. (2011). Tecnologia da informação e sustentabilidade: levantamento das principais práticas verdes aplicadas à área de tecnologia. Gerais: Revista Interinstitucional de Psicologia, 4(2), 159-172.

Malhotra, A., Melville, N. P., \& Watson, R. T. (2013). Spurring impactful research on information systems for environmental sustainability. MIS Quarterly, 37(4), 1265-1274.

Melville, N. (2010). IS innovation for environmental sustainability. MIS Quarterly, 34(1), 1-21.

Molla, A., \& Abareshi, A. (2012). Organizational green motivations for information technology: empirical study. Journal of Computer Information Systems, 52(3), 92-102. 
Molla, A., Cooper, V., Corbitt, B., Deng, H., Peszynski, K., Pittayachawan, S., \& Teoh, S. (2008, December). E-readiness to G-readiness: developing a green information technology readiness framework. Proceedings of the Australasian Conference on Information Systems, Canterbury, Christchurch, New Zealand, 19.

Murugesan, S. (2008). Harnessing green IT: principles and practices. IT professional, 10(1), 24-33. doi: 10.1109/MITP.2008.10

Murugesan, S. (2010). Making IT green. IEEE IT Professional, 12(2), 4-5.

Orlikowski, W. (1992). The duality of technology: rethinking the concept of technology in organizations. Organization Science, 3(3), 398-427.

Orsato, R. J. (2006). Competitive environmental strategies: when does it pay to be green? California Management Review, 48(2), 127-143. doi: 10.2307/41166341

Ozturk, A., Umit, K., Medeni, I. T., Ucuncu, B., Caylan, M., Akba, F., \& Medeni, T. (2011). Green ICT (information and communication technologies): a review of academic and practitioner perspectives. International Journal of eBusiness and eGovernment Studies, 3(1), 1-16.

Porter, M., \& Linde, C. van der (1995). Green and competitive: ending the stalemate. Harvard Business Review, 73(5), 120-134.

Santos, C., Nascimento, L., \& Neutzling, D. (2014). A gestão dos resíduos de equipamentos eletroeletrônicos (REEE) e as consequências para a sustentabilidade: as práticas de descarte dos usuários organizacionais. Revista Capital Científico-Eletrônica, 12(1), 78-96. Recuperado de http://www.spell.org.br/documentos/ver/33095/a-gestao-dos-residuos-de-equipamentoseletroeletronicos--reee--e-as-consequencias-para-a-sustentabilidade--as-praticas-de-descartedos-usuarios-organizacionais

Schmidt, N., Erek, K., Kolbe, L., \& Zarnekow, R. (2010, August). Predictors of green IT adoption: implications from an empirical investigation. Proceedings of the Americas Conference on Information Systems, Lima, Peru, 16.

Siqueira, M. L. de, \& Machado, C. M. C. (2013). Atividade extensionista e TI verde conectando instituição e comunidade. Revista Brasileira de Computação Aplicada, 5(2), 18-27. doi: 10.5335/rbca.2013.3271

Slaper, T., \& Hall, T. (2011). The triple bottom line: what is it and how does it work? The Indiana Business Review, 86(1), 4-8.

Vanchon, S., \& Klassen, R. D. (2006). Green project partnership in the supply chain: the case of the package printing industry. Journal of Cleaner Production, 14(6/7), 661-671. doi: 10.1016/j.jclepro.2005.07.014

Watson, R. T., Boudreau, M.-C., \& Chen, A. J. (2010). Information systems and environmentally sustainable development: energy informatics and new directions for the IS community. MIS Quarterly, 34(1), 23-38.

World Commission on Environment and Development. (1987). Our common future. London: Oxford University Press.

Yin, R. (2001). Estudo de caso: planejamento e métodos (2a ed.). Porto Alegre: Bookman. 


\section{Dados dos Autores}

\section{Ana Carolina Salles}

Av. Itália, km 8, s/n, Carreiros, 96203-900, Rio Grande, RS, Brasil. E-mail: salles.ac@bol.com.br

Ana Paula Ferreira Alves

Rua Washington Luiz, 855, Centro, 90010-460, Porto Alegre, RS, Brasil. E-mail: anapfalves@ gmail.com

Décio Bittencourt Dolci

Av. Itália, km 8, s/n, Carreiros, 96203-900, Rio Grande, RS, Brasil. E-mail: dbdolci@ gmail.com

Guilherme Lerch Lunardi

Av. Itália, km 8, s/n, Carreiros, 96203-900, Rio Grande, RS, Brasil. E-mail: gllunardi @ furg.br 


\section{ANEXO}

\section{Questões do Roteiro Semiestruturado}

1. Que práticas de TI Verde a empresa adota?

2. Quais foram os motivos que levaram a empresa a implantar projetos sustentáveis na área de TI? Motivo Principal? Motivos acessórios?

3. Qual o sentimento que a empresa tem de saber que está aplicando práticas sustentáveis?

4. Quais os resultados percebidos?

5. A empresa oferece fiscalização e mecanismos de controle para mensurar os resultados obtidos, decorrentes da adoção de projetos verdes?

6. Quais foram as práticas mais complicadas e as mais fáceis de realizar (Em qualquer categoria de dificuldade/ facilidade)? Por quê?

7. Estas novas ações são percebidas pelos clientes, ou seja, são externalizadas?

8. Como a empresa tomou conhecimento sobre TI Verde?

9. Que outras preocupações - fora da área de TI - a empresa tem a respeito de sustentabilidade?

10. A empresa possui outras práticas verdes implantadas dentro da organização?

11. Como a empresa encara o custo proposto pelo investimento de uma tecnologia sustentável? 